\title{
135. Studies on Inflammability of Hydrogen.
}

$X$. On the Prevention of Flame Propagation in Hydrogen-Air Mixtures.

By Yoshio Tanaka and Yûzaburô NagaI.

Aeronautical Research Institute, Tokyo Imperial University.

(Rec. Oct. 7, 1929. Comm. by K. TaWAra, Nov. 13, 1929.)

The hydrogen-air mixtures were allowed into the glass tube of $27 \mathrm{~mm}$. in internal diameter and 1 meter long, which was open at one end and closed at the other. The mixtures were fired at the open end and it was observed whether the flame passed over or was extinguished by the copper-gauge, which had been placed on its way, as shown in Fig. I.

Fig. $\quad$.

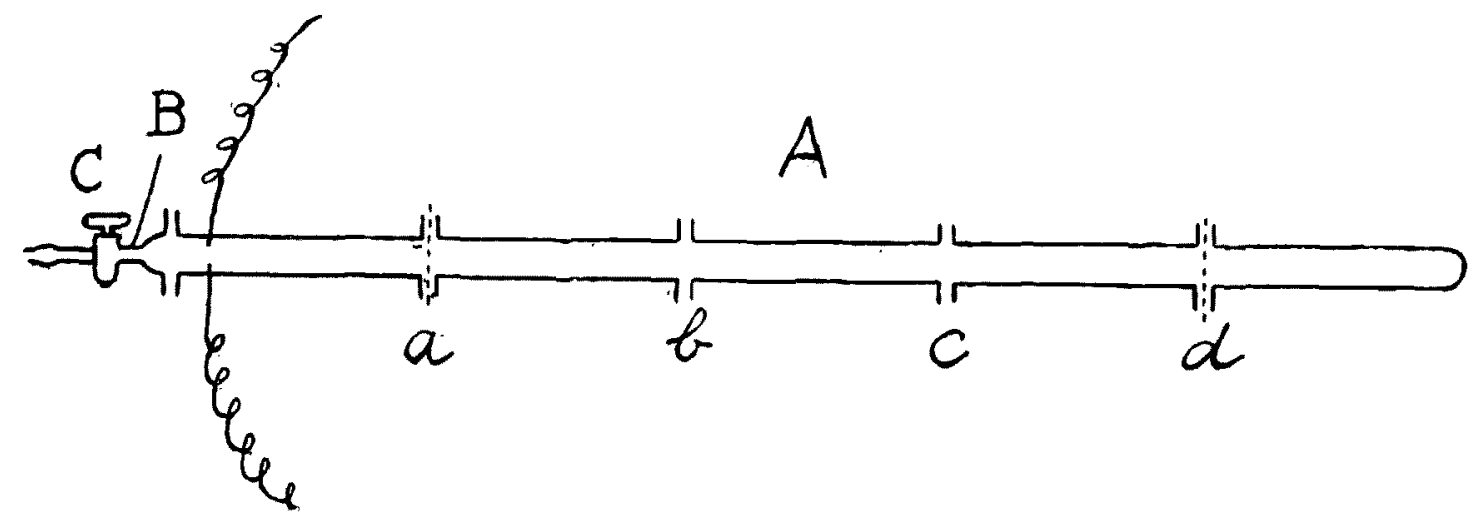

The following specimens of the gauge were used:

Table I. Copper-gauge used in the experiment.

\begin{tabular}{c|c|c}
\hline $\begin{array}{c}\text { No. of gauge } \\
\text { specimens. }\end{array}$ & $\begin{array}{c}\text { Number of } \\
\text { meshes in sq. cm. } \\
\text { of gauge. }\end{array}$ & $\begin{array}{c}\text { Weight of 1 sq. } \\
\text { cm. of gauge. }\end{array}$ \\
\hline$(1)$ & 37 & 0.16 \\
$(2)$ & 66 & 0.12 \\
$(3)$ & 106 & 0.10 \\
$(4)$ & 130 & 0.074 \\
$(5)$ & 240 & 0.051 \\
$(6)$ & 330 & 0.063 \\
$(7)$ & 500 & 0.049 \\
$(8)$ & 900 & 0.069 \\
\hline
\end{tabular}


In the following Tables, the figures $a$ and $d$ denote that the gauge was placed at $10 \mathrm{~cm}$. apart from the open or the closed end respectively (Fig. I.).

Table II. Copper gauge with largest meshes, which prevents the flame propagation in hydrogen-air mixtures.

\begin{tabular}{|c|c|c|c|c|c|}
\hline \multicolumn{2}{|c|}{$\begin{array}{l}\text { Composition of mixtures } \\
(\text { mol } \%) .\end{array}$} & \multicolumn{2}{|c|}{ No. of gauge. } & \multicolumn{2}{|c|}{$\begin{array}{l}\text { Number of meshes in } \\
1 \mathrm{sq} . \mathrm{cm} \text {. of gauge. }\end{array}$} \\
\hline $\mathrm{H}_{2}$ & Air & $a$ & $d$ & $a$ & $d$ \\
\hline 10 & 90 & (1) & (3) & 37 & 106 \\
\hline 20 & 80 & (6) & (6) & 330 & 330 \\
\hline 30 & 70 & (6) & $\begin{array}{l}\text { not prevented } \\
\text { by }(8)\end{array}$ & 330 & $>900$ \\
\hline 40 & 60 & (8) & $\begin{array}{l}\text { not prevented } \\
\text { by }(8)\end{array}$ & 900 & $>900$ \\
\hline 50 & 50 & (3) & (2) & 106 & 66 \\
\hline 60 & 40 & (2) & (2) & 66 & 66 \\
\hline 70 & 30 & (1) & - & 37 & - \\
\hline
\end{tabular}

Table III. Copper gauge with largest meshes, which prevents the flame propagation in hydrogen-Sn( $\left(\mathrm{CH}_{3}\right)_{4}$-air mixtures.

\begin{tabular}{|c|c|c|c|c|c|c|}
\hline \multicolumn{3}{|c|}{ Composition of mixtures $(\mathrm{mol} \%)$} & \multicolumn{2}{|c|}{ No. of gauge. } & \multicolumn{2}{|c|}{$\begin{array}{l}\text { Number of meshes in } \\
1 \text { sq. cm. of gaugg. }\end{array}$} \\
\hline $\mathrm{H}_{2}$ & $\mathrm{Sn}\left(\mathrm{CH}_{3}\right)_{4}$ & Air & $a$ & $d$ & $a$ & $d$ \\
\hline 10 & 0.20 & 89.80 & (1) & (2) & 37 & 66 \\
\hline 20 & 0.20 & 79.80 & (5) & (6) & 240 & 330 \\
\hline 30 & 0.20 & 69.80 & (5) & (8) & 240 & 900 \\
\hline 40 & 0.20 & 59.80 & (1) & (3) & 37 & 106 \\
\hline 10 & 0.50 & 89.50 & (1) & (1) & 37 & 37 \\
\hline 20 & 0.50 & 79.50 & (5) & (7) & 240 & 500 \\
\hline 30 & 0.50 & 69.50 & (1) & (3) & 37 & 106 \\
\hline 40 & 0.50 & 59.50 & (1) & (1) & 37 & 37 \\
\hline 10 & 1.00 & 89.00 & (1) & (3) & 37 & 106 \\
\hline 20 & 1.00 & 79.00 & (3) & (6) & 106 & 330 \\
\hline 30 & 1.00 & 69.00 & (1) & (1) & 37 & 37 \\
\hline
\end{tabular}

Table IV. Copper gauge with largest meshes, which prevents the flame propagation in hydrogen- $\mathrm{Pb}\left(\mathrm{CH}_{3}\right)_{4}$-air mixtures.

\begin{tabular}{|c|c|c|c|c|c|c|}
\hline \multicolumn{3}{|c|}{ Composition of mixtures $\left(\mathrm{mol} \%_{0}\right)$. } & \multicolumn{2}{|c|}{ No. of gauge. } & \multicolumn{2}{|c|}{$\begin{array}{l}\text { Number of meshes in } \\
1 \text { sq. cm. of gauge. }\end{array}$} \\
\hline $\mathrm{H}_{2}$ & $\mathrm{~Pb}\left(\mathrm{CH}_{3}\right)_{4}$ & Air & $a$ & $d$ & $a$ & $d$ \\
\hline 10 & 0.20 & 89.80 & (1) & (5) & 37 & 240 \\
\hline 20 & 0.20 & 79.80 & (5) & (6) & 240 & 330 \\
\hline 30 & 0.20 & 69.80 & & $\begin{array}{l}\text { not prevented } \\
\text { by (s) }\end{array}$ & 500 & $>900$ \\
\hline 40 & 0.20 & 59.80 & (5) & (5) & 240 & 240 \\
\hline
\end{tabular}


Table V. Copper gauge with largest meshes, which prevents the flame propagation in hydrogen-benzen-air mixtures.

\begin{tabular}{|c|c|c|c|c|c|c|}
\hline \multicolumn{3}{|c|}{ Composition of mixtures ( $\mathrm{mol} \%$ ) } & \multicolumn{2}{|c|}{ No. of gauge. } & \multicolumn{2}{|c|}{$\begin{array}{l}\text { Number of meshes in } \\
1 \text { sq. cm. of gauge. }\end{array}$} \\
\hline $\mathrm{H}_{2}$ & $\mathrm{C}_{6} \mathrm{H}_{6}$ & Air & $a$ & $d$ & $a$ & $d$ \\
\hline 10 & 0.50 & 89.50 & (3) & $(6)$ & 106 & 330 \\
\hline 20 & 0.50 & 79.50 & $(5)$ & (7) & 240 & 500 \\
\hline 30 & 0.50 & 69.50 & (5) & $\begin{array}{l}\text { not prevented } \\
\text { by }(8)\end{array}$ & 240 & $>900$ \\
\hline 40 & 0.50 & 59.50 & (2) & $(2)$ & 66 & 66 \\
\hline 10 & 1.00 & 89.00 & (4) & (6) & 130 & 330 \\
\hline 20 & 1.00 & 79.00 & (5) & $\begin{array}{l}\text { not prevented } \\
\text { by }(8)\end{array}$ & 240 & $>900$ \\
\hline 30 & 1.00 & 69.00 & (3) & $(7)$ & 106 & 500 \\
\hline
\end{tabular}

Table VI. Copper gauge with largest meshes, which prevents the flame propagation in hydrogen-Sn( $\left(\mathrm{CH}_{3}\right)_{4}$ - $\mathrm{CCl}_{4}$-air mixtures.

\begin{tabular}{|c|c|c|c|c|c|c|c|}
\hline \multicolumn{4}{|c|}{ Composition of mixtures $(\mathrm{mol} \%)$} & \multicolumn{2}{|c|}{ No. of gauge. } & \multicolumn{2}{|c|}{$\begin{array}{l}\text { Number of meshes in } \\
1 \mathrm{sq} . \mathrm{cm} \text {. of gauge. }\end{array}$} \\
\hline $\mathbf{H}_{2}$ & $\mathrm{Sn}\left(\mathrm{CH}_{3}\right)_{4}$ & $\mathrm{CCl}_{4}$ & Air & $a$ & $d$ & $a$ & $d$ \\
\hline 30 & 0.2 & 1.0 & 68.8 & (5) & (8) & 240 & 900 \\
\hline 30 & 0.5 & 2.0 & 67.5 & (1) & (5) & 37 & 240 \\
\hline
\end{tabular}

Some of these results are plotted in Fig. II.

From these results, it can be seen that the extinction of the flame propagating in the $\mathrm{H}_{2}$-air mixtures becomes far easier, if the explosion-suppressors," such as tetra-methyl tin, tetra-methyl lead, benzene etc., are added to the mixtures in small amounts. This fact is due to the rise of theoretical flame propagation temperature of hydrogen caused by addition of these explosion-suppressors, because, for the propagation of the flame, its temperature must be higher than theoretical flame propagation temperature of hydrogen, and the rise of theoretical flame propagation temperature means the smaller amount of heat, which is to be lost from the flame for the extinction.

The speed of flame is, generally, far higher at $d$ position than at $a$ position. Therefore, the time of contact of the flame with the gauge is far smaller at $d$ than at $a$, resulting in that the gauge with smaller meshes must be used at $d$ for the extinction of the flame.

1) Y. Tanaka and Y. Nagai, Proc., 5 (1929), 80. 
No. 9.]

Studies on Inflammability of Hydrogen.

The results of experiment in the above tables shows that this is the case.

Fig. II.

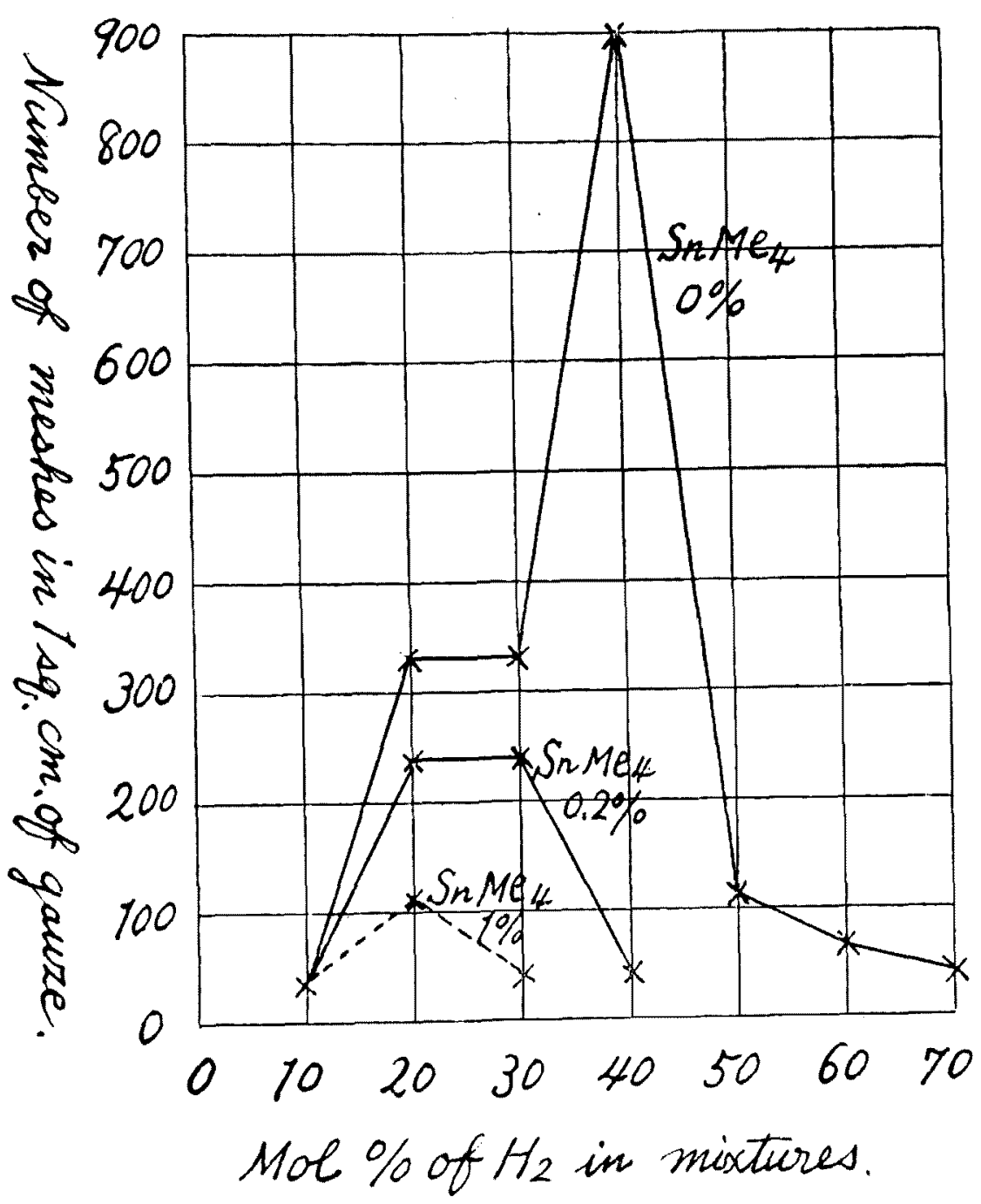

